\title{
Numerical Evaluation of Embedded Smart Irrigation System for Deep-Rooted Desert Trees
}

\author{
Qazi U. Farooq", Muhammad T. Naqash, Abdelkader T. Ahmed \\ Department of Civil Engineering, Islamic University of Madinah, 42351, Madinah, Saudi Arabia \\ Received October 11, 2021; Revised January 17, 2022; Accepted February 8, 2022
}

\section{Cite This Paper in the following Citation Styles}

(a): [1] Qazi U. Farooq, Muhammad T. Naqash, Abdelkader T. Ahmed, "Numerical Evaluation of Embedded Smart Irrigation System for Deep-Rooted Desert Trees," Civil Engineering and Architecture, Vol. 10, No. 2, pp. 470-476, 2022. DOI: 10.13189/cea.2022.100207.

(b): Qazi U. Farooq, Muhammad T. Naqash, Abdelkader T. Ahmed (2022). Numerical Evaluation of Embedded Smart Irrigation System for Deep-Rooted Desert Trees. Civil Engineering and Architecture, 10(2), 470-476. DOI: 10.13189/cea.2022.100207.

Copyright $\mathrm{C} 2022$ by authors, all rights reserved. Authors agree that this article remains permanently open access under the terms of the Creative Commons Attribution License 4.0 International License

\begin{abstract}
Kingdom of Saudi Arabia's green initiative program aims to plant ten million trees across the country. The kingdom mostly has a desert climate with constrained water resources. The sand dunes and sheets spread across hundreds of square kilometers in the country. The plantation of trees and saplings in these harsh conditions cannot be achieved without an efficient irrigation system. Native desert trees have deep roots and smart irrigation techniques can be intrinsically applied to irrigate these plants, even in the wild. In this study, a smart irrigation system for deep-rooted trees has been numerically assessed for the sandy desert conditions. The partially saturated, subsurface flow analysis has been done by using FEM modeling. The study results exhibit the possible placement of smart irrigation diffusers along with the depth. The method can be used to irrigate only the target root zone and oblige in water conservation. The field installation of a smart irrigation system in deep strata and its long-term maintenance will be some of the prospective challenges for field engineers.
\end{abstract}

Keywords Sandy Soil, Smart Irrigation, Effective Saturation, Root zone, Richard's Equation

\section{Introduction}

The Middle East and Saudi Arabia's green initiative is a regional and national program to combat climate change and enhance environmental protection. The program plans to plant ten million trees across the kingdom [1]. The country has vast barren lands in the form of deserts and has severe water shortage [2]. The kingdom has extensive geography and climatic conditions vary along the latitude and elevation, but mostly the weather is dry and summer months receive limited precipitation [3]. The rainfall patterns for most of the regions are not reliable [4] for sustainable plant growth.

The agricultural activities and urban greenery in Saudi Arabia entirely depend on irrigation. Traditionally the groundwater resources were utilized for the rationale but they are rapidly diminishing [5], [6]. To enhance the water conservation, pivot and sprinkler irrigation methods for agriculture and drip irrigation techniques for urban landscaping are adopted. However, water consumption and irrigation system efficiency are the major concerns in the kingdom's water sector [7]. The harsh climate coupled with a loss in irrigation systems leads to plant damage. The dry tree due to a damaged drip irrigation system can be seen in Figure 1. The palms in the background are still green due to the access to irrigated water. The picture is taken on September 2021 at Al-Jamia district of Madinah Saudi Arabia. The trees are planted and maintained at median strips of Al-Madinah city.

Irrigation systems combined with automated water supply and monitoring systems, or smart irrigation systems are replacing the conventional irrigation methods. Their efficiency has been proven at various scales, yet their application and adoptability have several challenges [8]. 


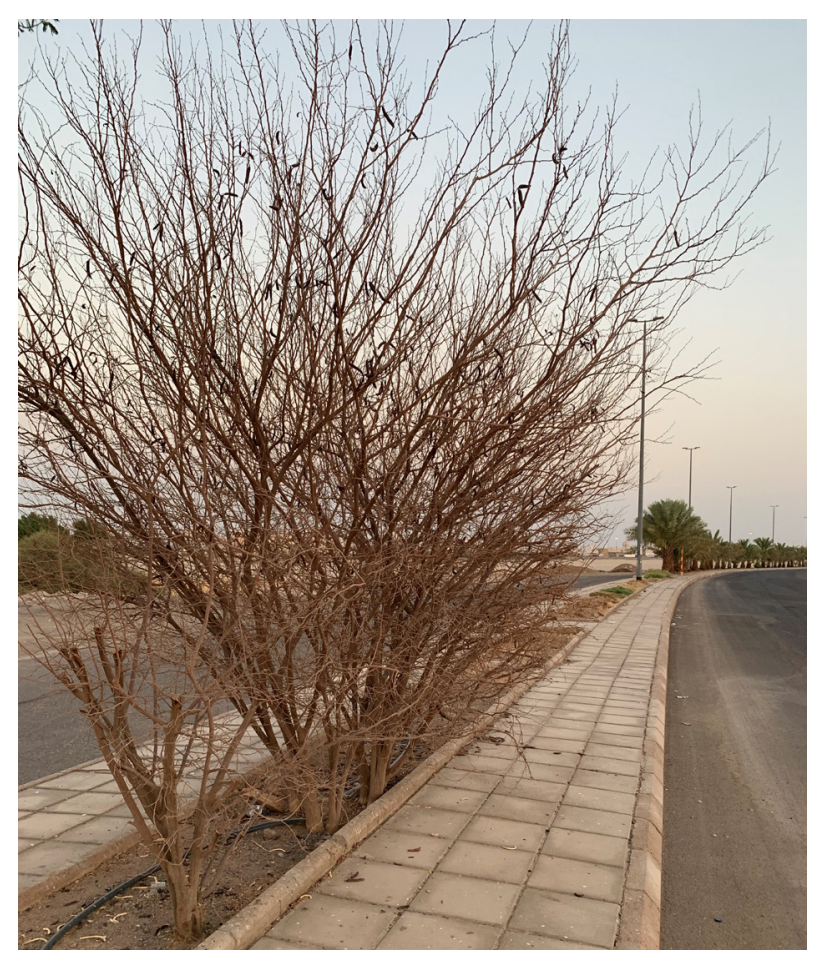

Figure 1. Drying sapling due to inadequate irrigation

The authors have previously studied the adaptability of complete subsurface smart irrigation system for perpetual crops in the arid climate with two different types of soils [9]. In this study, a deep-rooted smart irrigation system for desert trees has been suggested; the schematic diagram of the proposed irrigation system is shown in Figure 2. The system is supplied by the embedded irrigation line which is connected by metallic pipe placed along with the depth near plant roots with multiple drippers. The material of the pipe can be selected as per soil resistance. The system has soil moisture detection equipment that can be programmed to the cutoff water supply when the required moisture level is attained in the root zone and once the retained water is utilized, the irrigation can be automatically restored. The primary objective of this study is to numerically evaluate the possibility of an irrigation system that is capable of saturation the root zone of the native trees while maintaining the evaporation and infiltration losses at the bare minimum.

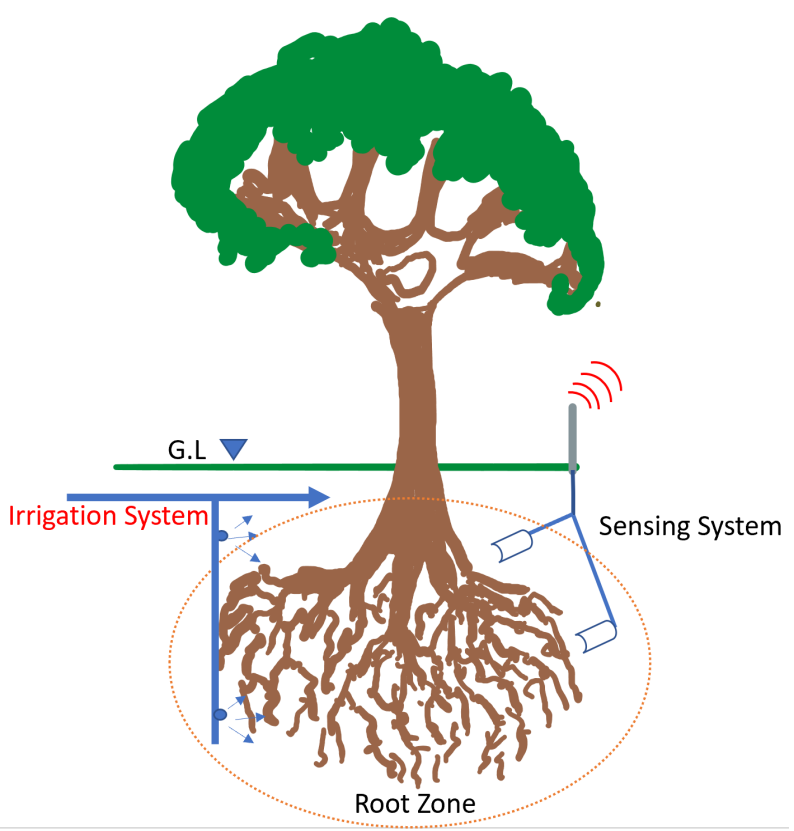

Figure 2. Schematic diagram of the deep smart irrigation system

The proposed technique can also be applied to other geotechnical problems where subsurface water flow and moisture content are of significance such as dams and flood embankments [10].

\section{Materials and Methods}

The sandy soil conditions of the Saudi Arabian desert are adopted for the appraisal of the deep-rooted smart irrigation system. The gradation curve of the sand sample taken from Al Madinah city is plotted in Figure 3. The soil comprises about $90 \%$ sand with nearly $10 \%$ gravel and negligible fines. It has a range of sand particles and has high uniformity as per ASTM/unified soil classification; it is designated as well-graded sand with the symbol SW [11]. The embedded smart irrigation system has been stimulated by two numerical test cases. Since desert sand has variation in relative density. The numerical tests were designed based on sand compaction levels. The test designation and the respective hydraulic properties of the sand are elaborated in Table 1 . The dense sand has low porosity and hydraulic conductivity as compared to the loose counterpart. 


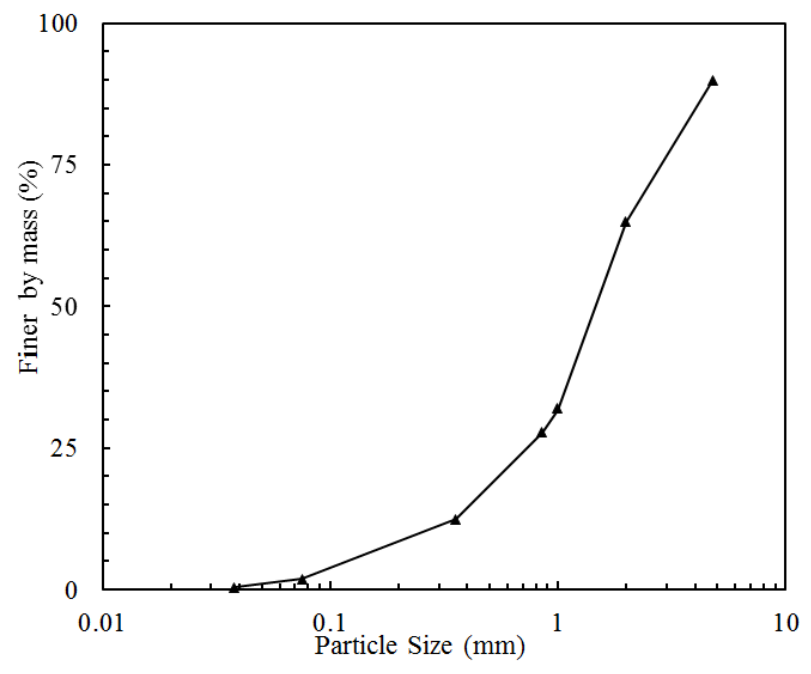

Figure 3. Particle size distribution of Madinah sand

Table 1. Test cases and respective soil parameters

\begin{tabular}{|c|c|c|c|}
\hline $\begin{array}{c}\text { Test } \\
\text { Designation }\end{array}$ & $\begin{array}{c}\text { Sand Density } \\
\mathbf{\rho}\left(\mathbf{k g} / \mathbf{m}^{\mathbf{3}}\right)\end{array}$ & $\begin{array}{c}\text { Porosity } \\
\mathbf{n}(\mathbf{\%})\end{array}$ & $\begin{array}{c}\text { Hydraulic } \\
\text { Conductivity } \\
\mathbf{k}(\mathbf{c m} / \mathbf{s})\end{array}$ \\
\hline Dense (D) & 1632 & 0.38 & 0.001 \\
\hline Loose (L) & 1450 & 0.42 & 0.032 \\
\hline
\end{tabular}

In this study, the partially saturated flow problem is modeled based on Richard's principle [12]. Richard's equation itself is based on Darcy's law for groundwater flow. It is a nonlinear partial differential equation that characterizes the movement of water in unsaturated soils. Mathematically it can be described as (1):

$$
(C+\Theta \xi) \frac{\partial \Psi}{\partial t}+\nabla \cdot[-k \nabla(\Psi+Z)]=0
$$
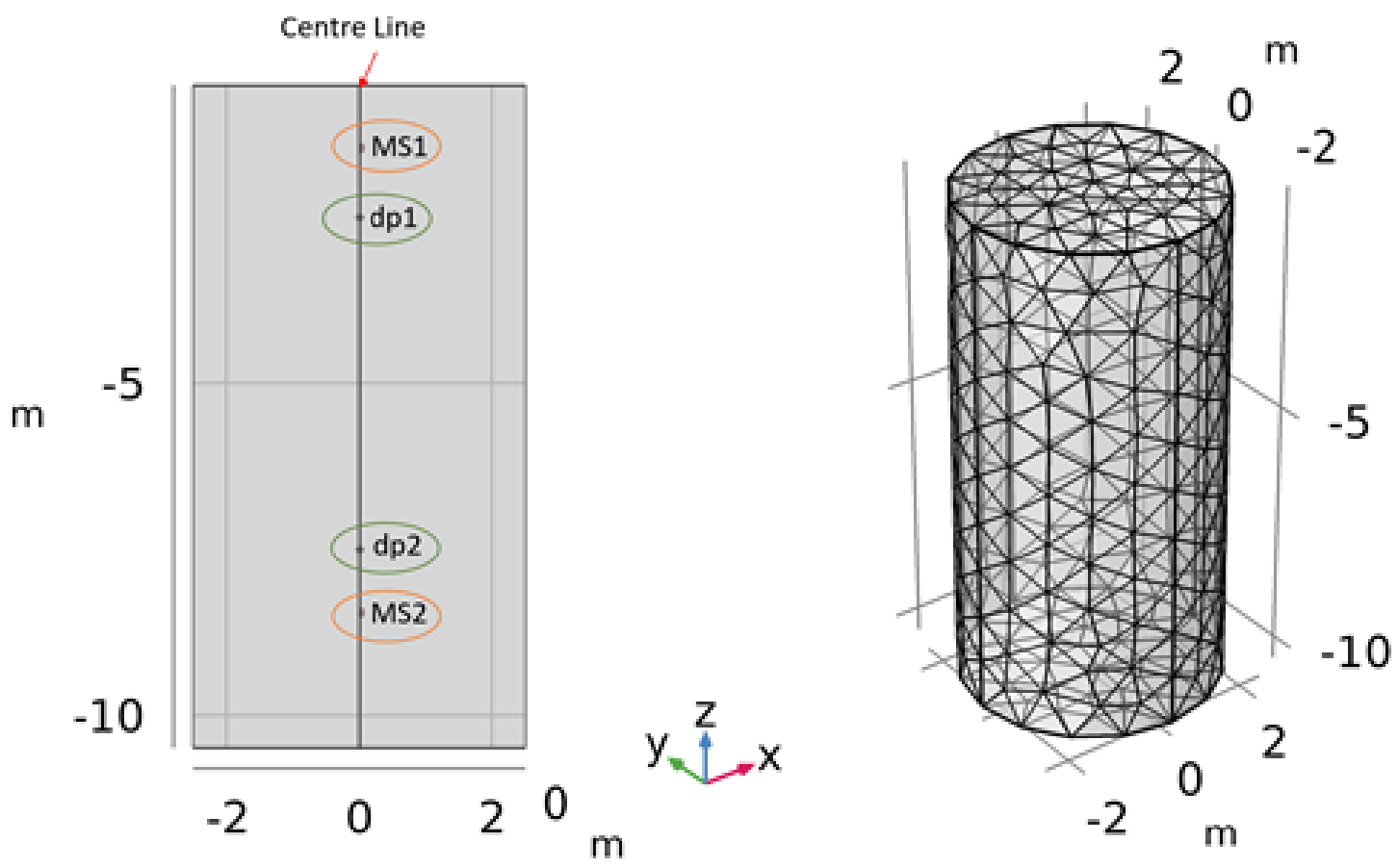

Where $C$ is specific moisture capacity per meter; $\Theta$ is effective soil saturation expressed in \%age of full saturation; $\xi$ is storage coefficient per unit length; $\psi$ is soil suction head in meters of water; $\mathrm{t}$ is time; $k$ is the coefficient of permeability, and $\mathrm{Z}$ is elevation. The basic parameter considered in this study is the normalized water content or effective saturation. Numerically it can be written as (2):

$$
\Theta=\left(\frac{\theta_{t}}{\theta_{s}}\right) \times 100 \%
$$

Where $\theta_{\mathrm{t}}$ is the volumetric water content at any stage and $\theta_{\mathrm{s}}$ is the water content at full saturation.

\subsection{Numerical Modelling}

The numerical simulation of the tree root system has been modeled by assuming a cylindrical geometry, having a $2.5 \mathrm{~m}$ radius and $10 \mathrm{~m}$ depth. The subsurface flow module of the COMSOL Multiphysics program has been used to perform FEM analysis [13]. The model geometry and the FEM mesh are shown in Figure 4. The water is supplied to the system by two irrigation drippers namely $\mathrm{dp}$ 1 and dp 2, placed respectively at 2.5- and 7.5-meter depth. The saturation condition is monitored by two moisture sensors (MS1 and MS2) placed at $1.5 \mathrm{~m}$ from the ground surface and base.

The seepage is allowed from all boundaries and the effect of gravity is considered in the analysis. The water is supplied at a rate of $0.5 \mathrm{~m} / \mathrm{sec}$. while the drippers have a diameter of $5 \mathrm{~cm}$. The water is continuously supplied for two hours in the numerical tests. The irrigation is started simultaneously from both the drippers at the same rate.

Figure 4. Geometry and model mesh for the deep root irrigation system 


\section{Results and Discussions}

Richard's equation results were simulated by using the retention model based on the soil water characteristics curve of the geo-material [14]. The main purpose of any irrigation system is to maintain the minimum saturation level in soil, which is suitable for plant growth. In other words, the soil moisture at any time should be well above the wilting point [15].

The normalized water content or effective saturation $(\Theta)$ is one of the primary parameters to determine the soil saturation condition. The effective saturation extends in the system after 15 miutes of irrigation for dense and loose soil is respectively shown in Figure 5 and Figure 6. The difference between the relative densities and saturation ratio can be seen from the figure as the post 15 minutes saturation zone for dense soil is quite smaller than that of the loose soil. The lowest saturation level reported in dense soil is $5.27 \%$ while it is $21.9 \%$ in the loose case.

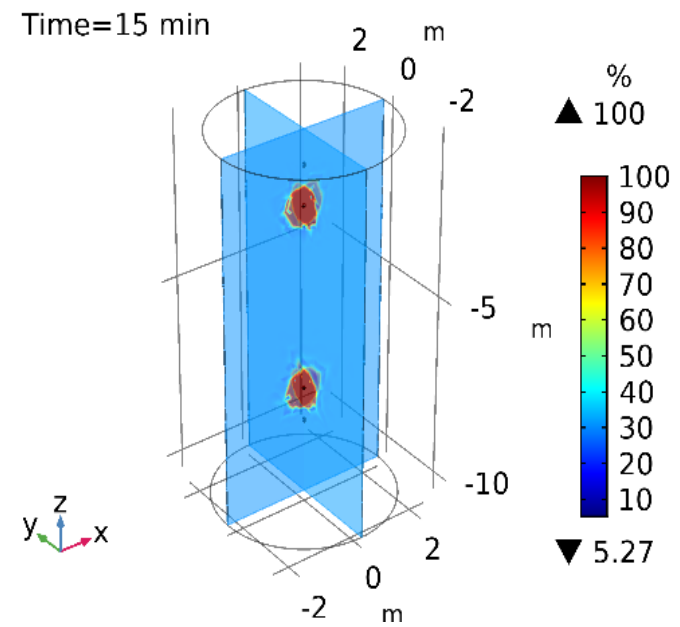

Figure 5. Initial development of saturation zone (dense soil)

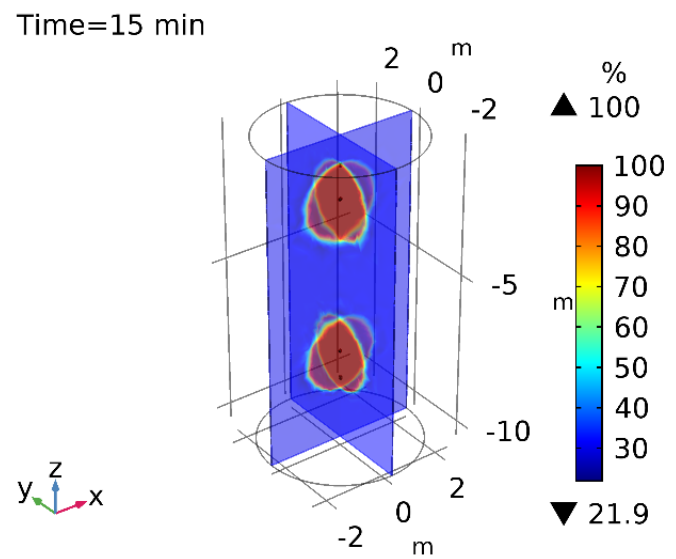

Figure 6. Initial development of saturation zone (loose Soil)
The saturation zones of test cases D and L after $1 \mathrm{hr}$ of irrigation can be compared from Figure 7 and Figure 8, at this instant, the water distribution in loose sand is still more widespread than the dense one however, the difference between the lowest saturation points is marginalized.

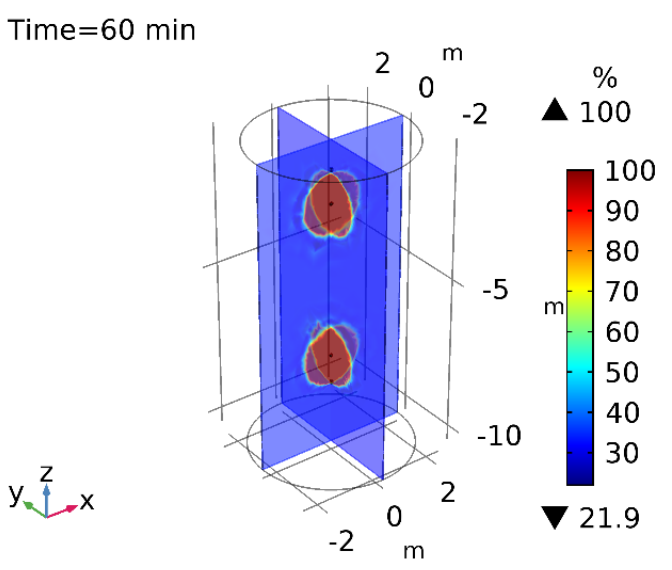

Figure 7. Saturation plot for dense sand after $1 \mathrm{hr}$. of irrigation

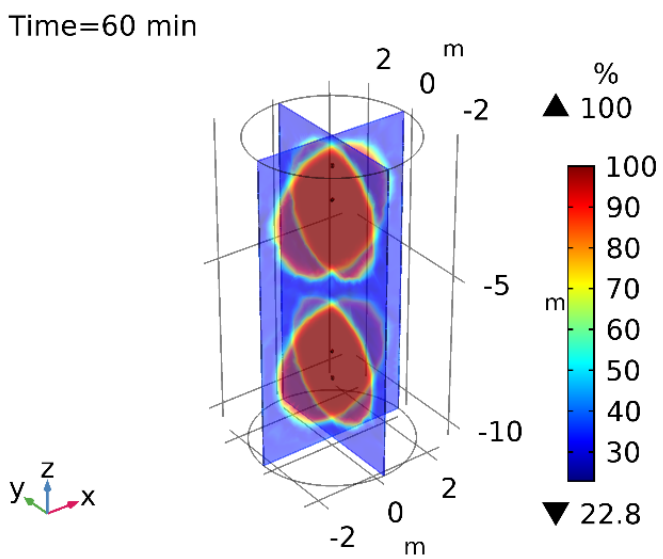

Figure 8. Saturation plot for loose sand after 1 hr. of irrigation

The difference of both cases at the end of the numerical test i.e., after 120 minutes can be seen from Figure 9 and Figure 10. The unsaturated portion in case L has almost tarnished and the approximately complete root zone is saturated. The saturation zone for the dense case D is almost similar to the 15 minutes saturation condition of the loose sand case (Figure 6) and still has several unsaturated areas.

The saturation response for the two studies cases is remarkably different. The main reason behind this scenario is the difference in permeability and void ratio. The compaction state of soil greatly affects these parameters and the flow rate must be regulated according to the relative density. 


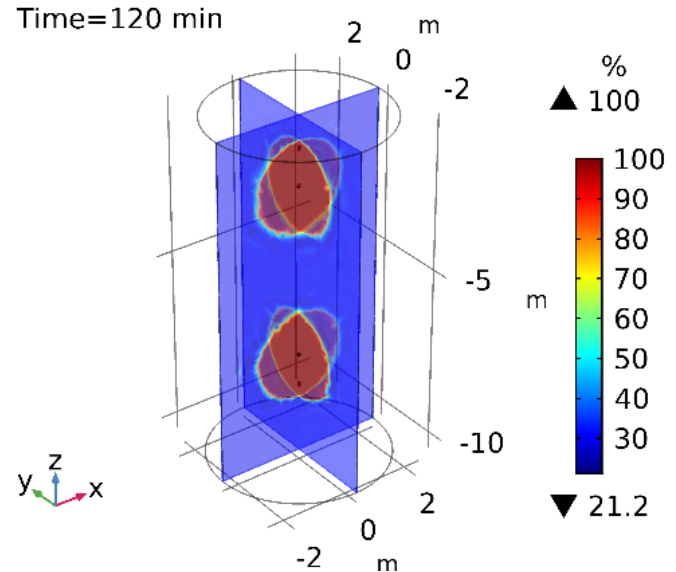

Figure 9. Saturation plot for dense sand after $2 \mathrm{hr}$. of irrigation

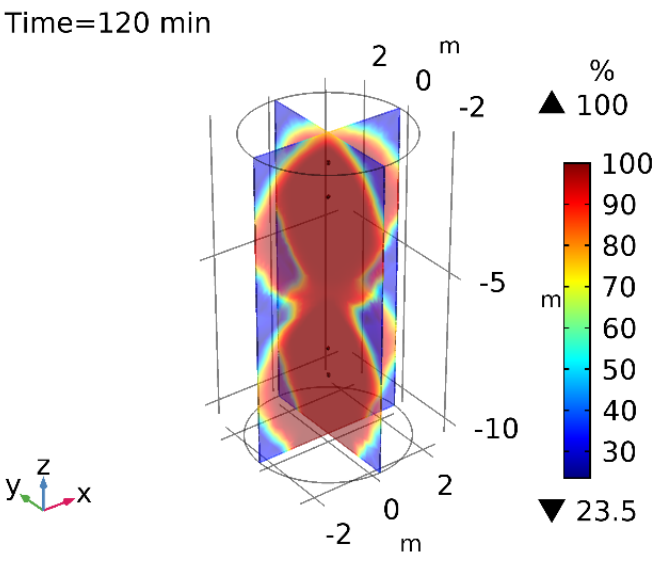

Figure 10. Saturation plot for loose sand after $2 \mathrm{hr}$. of irrigation

The development of porewater pressure with subsurface irrigation is one of the primary concerns. Since the probability of porewater pressure buildup depends on the drainage condition, the flow rate and permeability greatly affect the soil response. The pressure profiles against depth for the loose and dense cases are respectively plotted in Figure 11 and Figure 12. The figures show the pressure profile along the centerline at 0,60 , and 120 mins. The negative pressure indicates the unsaturated zone, whilst the positive values are porewater pressure. The negative pressure zones exhibit soil suction where the soil still has the tendency to absorb more water. The sharp positive pore pressure peaks were observed near the location of the drippers. Though their distribution is quite narrow, the peak pressure values after two hours of irrigation are remarkably different for both soils, at the same flow rate of $0.5 \mathrm{~m} / \mathrm{sec}$. the peak pressure values differ by $300 \%$.

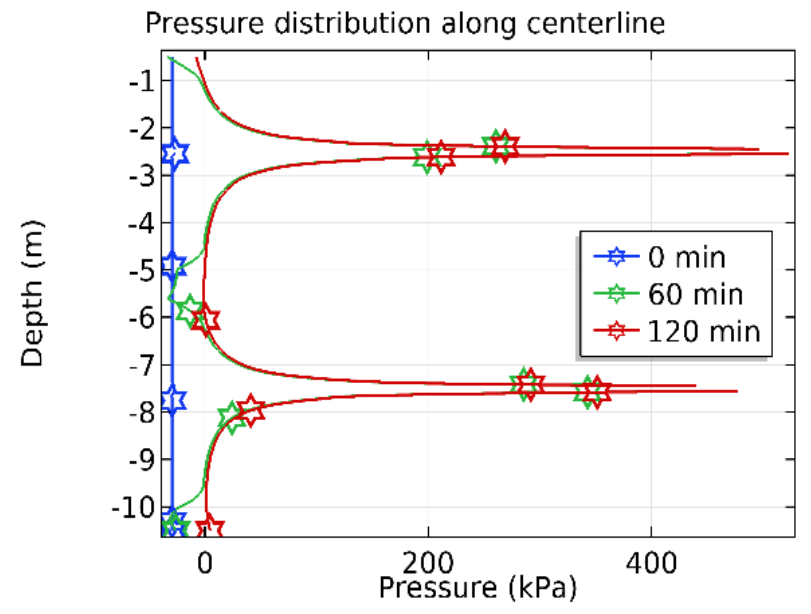

Figure 11. Pressure variation along the centerline for loose sand

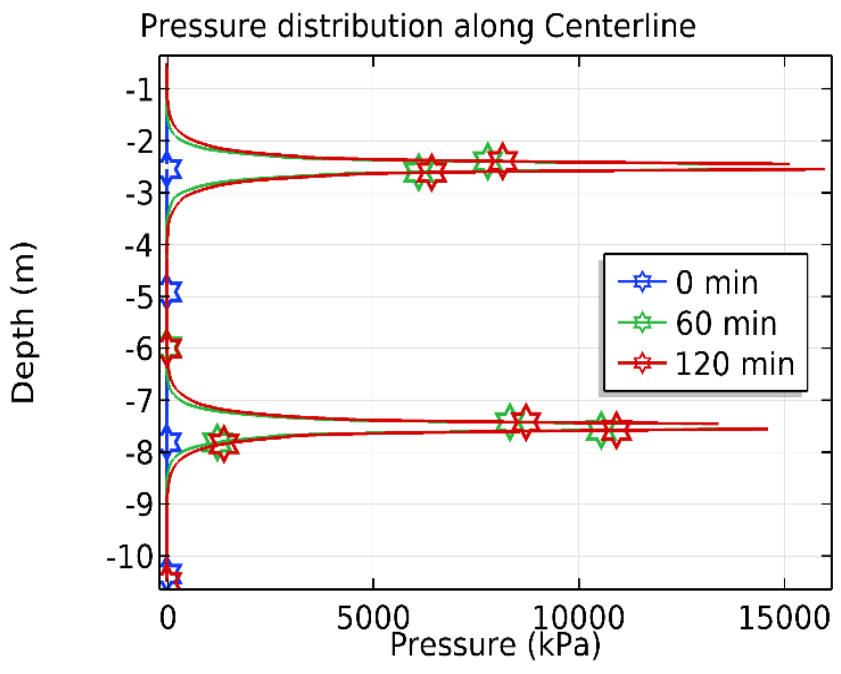

Figure 12. Pressure variation along the centerline for dense sand

The FEM analysis results for both dense and loose sand cases are summed up in Figure 13. It takes less than ten minutes to saturate the required area for the loose sand, with the lower region having a slightly higher period. The dense sand takes one hour to achieve the same saturation level. The upper and lower readings for the dense sand case are very consistent. The two-hour saturation cycle was long enough for both cases. In a real-life situation, the moisture monitoring system can be synchronized with the water supply system and the irrigation can be terminated well before a numerically tested threshold value of two hours.

The suction forces in the soil will retain the saturation level for a certain period until the plant utilizes the water and saturation falls below the minimum design value. The IoT-based system can then restart the irrigation cycle. 
Saturation History

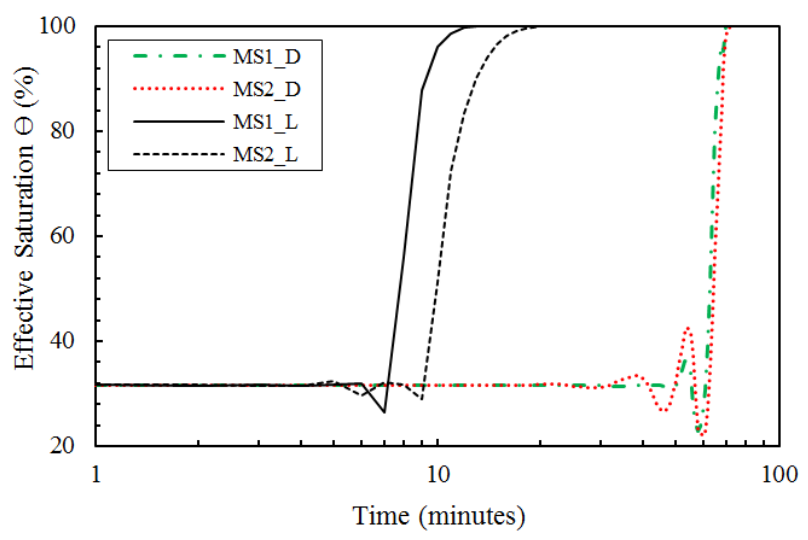

Figure 13. Summary of the saturation data

\section{Conclusions}

In the light of numerical analysis results and the above discussions following conclusions can be drawn:

1. The analysis of the subsurface flow model on partially saturated sand confirms that along depth smart irrigation system can be adopted for trees of desert climate where groundwater is unavailable.

2. The system is expected to create a limited saturated zone surrounding the plant roots which can be easily sustained by using IoT-based sensing and dripping system.

3. The system's effectiveness greatly depends on the hydraulic conductivity and relative density of the sand. Loose sands can be easily saturated and vice versa.

4. Pore pressure buildup has been observed near inflow points, though the extent of pore water pressure is limited its numerical value particularly in dense soil cases is quite high. Irrigation and pore pressure cycles can lead to structural instability. The situation can be controlled by avoiding longer irrigation duration and higher flow rates.

The study presents the fundamental idea about the embedded irrigation systems, a customized mathematical model for partially saturated conditions on different geographic soils can be an interesting topic of further research. The hydraulic design and material selection for the embedded irrigation pipes and their possible clogging with time is required to be studied in detail for the practical application of the presented concept.

\section{Acknowledgments}

The authors extend their appreciation to the Deputyship of Research \& Innovation, Ministry of Education in Saudi Arabia, to fund this research work through the project number (20/9).

\section{REFERENCES}

[1] Saudi Green Initiative, "Saudi Green Initiative," The Kingdom's journey towards 10 billion trees, 2021. https://www.saudigreeninitiative.org/.

[2] H. S. Edgell, Arabian Deserts. Dordrecht: Springer Netherlands, 2006.

[3] H. Hasanean and M. Almazroui, "Rainfall: Features and variations over Saudi Arabia, a review," Climate. 2015, doi: 10.3390/cli3030578

[4] Q. U. Farooq and M. T. Naqash, "Performance of Shallow Building Foundations under Infrequent Rainfall Patterns at Al-Madinah, Saudi Arabia," The Open Civil Engineering Journal, vol. 15, no. 1, pp. 91-103, Apr. 2021, doi: $10.2174 / 1874149502115010091$.

[5] A. A. Al-Ibrahim, "Excessive use of groundwater resources in Saudi Arabia: Impacts and policy options," $A M B I O$, 1991, doi: $10.2307 / 4313768$.

[6] O. A. Fallatah, "Groundwater Quality Patterns and Spatiotemporal Change in Depletion in the Regions of the Arabian Shield and Arabian Shelf," Arabian Journal for Science and Engineering, 2020, doi: 10.1007/s13369-019-04069-1.

[7] S. S. Gabr, E. F. Farg, T. M. Habeebullah, and S. M. Arafat, "Irrigation water consumption and its impact on the groundwater aquifer of Wadi Uranah, Makkah, Saudi Arabia using remote sensing techniques," Egyptian Journal of Remote Sensing and Space Science, 2020, doi: 10.1016/j.ejrs.2018.10.001.

[8] L. García, L. Parra, J. M. Jimenez, J. Lloret, and P. Lorenz, "IoT-Based Smart Irrigation Systems: An Overview on the Recent Trends on Sensors and IoT Systems for Irrigation in Precision Agriculture," Sensors, vol. 20, no. 4, p. 1042, Feb. 2020, doi: 10.3390/s20041042.

[9] Q. U. Farooq, M. T. Naqash, A. T. Ahmed, and B. A. Khawaja, "Optimization of Subsurface Smart Irrigation System for Sandy Soils of Arid Climate," Modelling and Simulation in Engineering, vol. 2021, pp. 1-14, Dec. 2021, doi: 10.1155/2021/9012496.

[10] L. Afriani, G. E. Susilo, S. Nawangrini, and I. Iswan, "Soil Shrinkage and Consolidation Study on Flood Embankments in Swamp irrigation Areas (Case Study: Tulang Bawang Indonesia)," Civil Engineering and Architecture, vol. 8, no. 6, pp. 1225-1233, Dec. 2020, doi: 10.13189/cea.2020.080 607.

[11] ASTM D2487-17e1, "Standard Practice for Classification of Soils for Engineering Purposes (Unified Soil Classification System)," ASTM International, West Conshohocken, PA, 2017.

[12] T. Fong, M. Chui, and D. L. Freyberg, "The Use of COMSOL for Integrated Hydrological Modeling," Proceedings of the COMSOL Conference 2007 Boston, pp. 217-223, 2007.

[13] Comsol, "Variably Saturated Flow (Comsol)," pp. 1-20, 2008. 
[14] M. T. van Genuchten, "A Closed-form Equation for Predicting the Hydraulic Conductivity of Unsaturated Soils," Soil Science Society of America Journal, vol. 44, no. 5, pp. 892-898, Sep. 1980, doi: 10.2136/sssaj1980.03615995004 $400050002 x$.
[15] N. Yao et al., "Permanent wilting point plays an important role in simulating winter wheat growth under water deficit conditions," Agricultural Water Management, vol. 229, 2020, doi: 10.1016/j.agwat.2019.105954. 